\title{
A diretriz do Plano Nacional de Pós-Graduação de articulação com a Educação Básica: relato do projeto Experimentando Ciência
}

\author{
Ana Estela Haddad*; Fábio Daumas Nunes*; Marcelo Cavalcanti*; Rodolfo Francisco Haltenhoff \\ Melani*; Paulo Henrique Braz-Silva*; Deise Garrido**; Ana Cristina Moraes Azevedo***; Lumena \\ Maria Keller da Rivera***; Sônia Tereza de Andrade***; Maria Cristina dos Santos Pereira***; \\ Marcel Valentino Bozzo***; Adriana Dall’Onder***; Claudia Regina Perazzolo***; Iara Maia \\ Covas***; Luciana Ribeiro da Silva Vieira***; Lucilene Limp***; Emelin Assef Jorge***; Elder \\ Ribeiro Garcia*; André Luiz Bafume****; Marcelo Bönecker*
}

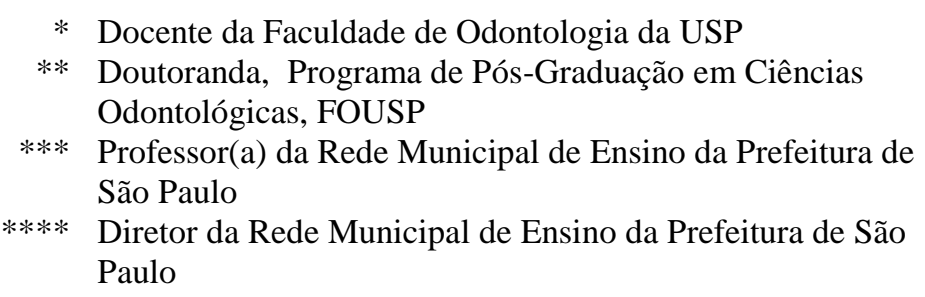

Recebido em 05/03/2017. Aprovado em 17/07/2017.

\begin{abstract}
RESUMO
O Plano Nacional de Pós-Graduação recomenda que o Sistema Nacional de Pós-Graduação desenvolva estudos tendo em vista as necessidades e os interesses dos estudantes da educação básica. Buscando seguir esta diretriz, o Programa de Pós-Graduação em Ciências Odontológicas da Faculdade de Odontologia da Universidade de São Paulo estabeleceu uma parceria com instâncias gestoras da rede pública de educação no município de São Paulo, formulando e implementando o projeto Experimentando Ciência. O objetivo foi de aproximar os estudantes do ensino fundamental do conhecimento científico produzido na universidade, promovendo a popularização da ciência e da tecnologia. A partir da delimitação de um problema em sala de aula, quatro grupos de dez alunos, percorriam cinco laboratórios da faculdade, com o objetivo de levantar hipóteses, ensaiar e testar desenhos experimentais. Participaram, ao longo do ano de 2016, cinco escolas, perfazendo um total de 200 alunos. Os resultados foram apresentados em conjunto na forma de relatórios, relatos de experiência, e divulgados para a comunidade escolar, no sentido de compartilhar e multiplicar o conhecimento. De acordo com os relatos, os estudantes tiveram a oportunidade de ampliar o entendimento da ciência de forma prática, instigando a curiosidade pela pesquisa e despertando a percepção de que a educação superior é uma etapa possível de ser alcançada no ciclo educacional. Para a universidade, o projeto demonstrou a viabilidade e importância da articulação interdisciplinar e entre os diferentes níveis educacionais.
\end{abstract}

Descritores: Ensino Fundamental e Médio. Ciência. Ciências da Saúde. Educação Superior. Capacitação de Recursos Humanos em Saúde. 


\section{INTRODUÇÃO}

A busca pela democratização do acesso e pela melhoria constante da qualidade da educação são elementos fundamentais para o desenvolvimento social e econômico de um país.

A política nacional de educação no Brasil, no período localizado entre 2003 e 2016, caracterizou-se por adotar uma visão sistêmica da educação, compreendendo a importância de não se priorizar determinado nível - ensino fundamental ou educação superior - mas sim fortalecer todas as etapas do processo educacional, buscando conectá-las, na pespectiva de que possam avançar articuladas e em sinergia. Não há como aumentar o número de mestres e doutores formados sem melhorar a eficiência do sistema como um todo, inclusive da educação básica. Sabe-se hoje que a educação infantil cumpre papel pedagógico e formativo fundante e decisivo para que a criança possa alcançar sucesso na alfabetização e ao longo de sua vida escolar. A equidade de oportunidades deve ser buscada pela política pública, portanto, desde o início.

O conceito de qualidade da educação é uma construção histórica que assume diferentes significados em tempos e espaços diversos e tem a ver com os lugares de onde falam os sujeitos, os grupos sociais a que pertencem, os interesses e valores envolvidos e os projetos de sociedade em jogo. $\mathrm{O}$ conceito de qualidade adotado nesse período pela política nacional de educação é bastante abrangente e envolve garantir o acesso e a permanência dos alunos à escola; promover as aprendizagens significativas do ponto de vista das exigências sociais e de desenvolvimento individual; atender às necessidades $\mathrm{e}$ às características dos estudantes de diversos contextos sociais e culturais, com diferentes capacidades e interesses; e tratar de forma diferenciada os estudantes, com vistas a obter aprendizagens e desenvolvimento equiparável, assegurando a todos a igualdade de direito à educação ${ }^{1}$.

Ao longo das últimas três décadas, sob a responsabilidade da Coordenação de Aperfeiçoamento de Pessoal de Nível Superior (CAPES)/Ministério da Educação, o Brasil construiu um bem sucedido sistema de PósGraduação que se constitui na parte mais exitosa do seu sistema de ensino, considerado, unanimemente, o maior e melhor da América Latina ${ }^{2}$. A produção científica brasileira alcançou o $15^{\circ}$ lugar no ranking mundial, e a Odontologia, o $2^{\circ}$ lugar, segundo o banco de dados de indicadores bibliométrios SCImago Journal \& Country Rank $^{3}$.

$\mathrm{Na}$ educação básica, o Brasil fez os seguintes avanços nas duas últimas décadas ${ }^{4}$ :

- obrigatoriedade da matrícula das crianças de 4 e 5 anos de idade na pré-escola (Emenda Constitucional n ${ }^{\circ}$ 59/2009)

- acesso ao ensino fundamental está quase universalizado;

- expansão da oferta de Educação Profissional - Programa Nacional de Acesso ao Ensino Técnico e Emprego (PRONATEC);

- redução das taxas de analfabetismo entre jovens e adultos, destacando-se que a taxa de analfabetismo das pessoas com 15 anos ou mais passou de 12,4\%, em 2001, para 8,7\%, em 2012 (Pesquisa Nacional por Amostra de Domicílios - PNAD 2012) ${ }^{6}$;

- aumento do financiamento da educação (6,4\% do PIB); e

- promulgação do Plano Nacional de Educação (2014-2024).

O Índice de Desenvolvimento da Educação Básica (Ideb) ${ }^{7}$, foi criado a partir de 2007 , com o objetivo de medir a qualidade do aprendizado nacional e estabelecer metas para a melhoria do ensino. Funciona como um indicador nacional que possibilita o monitoramento da qualidade da 
educação pela população por meio de dados concretos, com o qual a sociedade pode se mobilizar em busca de melhorias. Para tanto, o Ideb é calculado a partir de dois componentes: a taxa de rendimento escolar (aprovação) e as médias de desempenho nos exames aplicados pelo Instituto Nacional de Estudos e Pesquisas Anísio Teixeira (Inep), vinculado ao Ministério da Educação (MEC). Os índices de aprovação são obtidos a partir do Censo Escolar, realizado anualmente. As metas estabelecidas pelo Ideb são diferenciadas para cada escola e rede de ensino, com o objetivo único de alcançar 6 pontos até 2022, média correspondente ao sistema educacional dos países desenvolvidos ${ }^{7}$.

O Plano Nacional de Pós Graduação (PNPG 2011-2020) $)^{8}$ tem como uma de suas diretrizes "atenção às atuais gerações de crianças e jovens, particularmente nas áreas de saúde e educação em ações voltadas para o ensino básico e superior com a participação da Pós-Graduação, pois dependerá dessas gerações o desempenho da economia brasileira nas próximas décadas, como membros da população em idade ativa, em um contexto de rápido crescimento, em termos absolutos e relativos, e de forte aumento da população idosa".

$\mathrm{O} \mathrm{PNPG}^{8}$ aponta que pós-graduação stricto sensu é a última etapa da educação formal e está diretamente ligada aos demais níveis de ensino, uma vez que os seus alunos são oriundos das etapas de ensino anteriores. Recomenda que o Sistema Nacional de Pós-Graduação (SNPG) desenvolva estudos relativos à formação de professores, ao estabelecimento de padrões mínimos de qualidade, à gestão das escolas e à adequação dos currículos, tendo em vista as necessidades e os interesses dos adolescentes e jovens sujeitos da educação básica, notadamente do ensino médio.

Em vista do exposto, o Programa de PósGraduação em Ciências Odontológicas da
Faculdade de Odontologia da USP (FOUSP) tomou a iniciativa de aproximar-se de instâncias gestoras do ensino fundamental no município de São Paulo e em parceria foi formulado e implementado o projeto Experimentando Ciência, que passamos a relatar.

\section{RELATO DE EXPERIÊNCIA}

O projeto Experimentando Ciência teve como objetivo, a partir da perspectiva do Programa de Pós-Graduação em Ciências Odontológicas, atender à diretriz de articulação entre a pós-graduação e a educação básica, e promover a popularização da ciência e tecnologia. Isto é, aproximar os estudantes da educação básica, do conhecimento científico mais recente, por meio da experimentação, na perspectiva da sua iniciação científica.

Do ponto de vista dos gestores e docentes responsáveis pela coordenação pedagógica do ensino fundamental vinculados à Diretoria Regional de Educação (DRE) do Butantã, destacam-se como objetivos gerais: a) a contextualização e ampliação dos conceitos estudados oferecendo condições de imersão nas práticas científicas, especialmente às relacionadas à experimentação; b) a formação continuada de professores em busca de uma transformação da ação na sala de aula e c) propiciar uma vivência ativa de grupos de estudantes em espaços educativos científicos que envolvam a aprendizagem.

\section{Planejamento}

Foram realizadas seis reuniões de planejamento, envolvendo as seguintes dimensões: apresentação dos participantes e das expectativas em relação ao projeto, de um lado, dos docentes que representavam o Programa de Pós-Graduação em em Ciências Odontológicas, e de outro, os gestores e professores do ensino fundamental de cinco escolas municipais da DRE 
Butantã; determinação dos objetivos e da abrangência do projeto; escolha das atividades a serem desenvolvidas; e estabelecimento do cronograma de trabalho.

\section{Espaços educativos na universidade}

Os seguintes espaços da FOUSP foram identificados pela equipe de planejamento do projeto como possibilidades de trabalho: biblioteca, Laboratório de Odontologia Forense, Laboratório de Imagem Radiológica, Laboratório de Microscopia e de Células, Laboratório de Patologia Molecular, Banco de Dentes e o Centro de Produções Digitais integrante do Núcleo de Telessaúde e Teleodontologia.

\section{Abrangência do projeto}

Participaram do projeto cinco escolas públicas municipais de ensino fundamental de São Paulo, com 40 alunos de cada escola, totalizando 200 estudantes de 11 a 15 anos de idade; coordenadores pedagógicos, professores de ciências e de língua portuguesa.

\section{Etapas}

A etapa 1 visou à formação continuada de professores, incluindo curso para atualização de conceitos básicos recentes; planejamento de subprojetos; e aperfeiçoamento em pesquisa científica (uso da biblioteca).

A etapa 2 compreendeu o ensino e a aprendizagem do aluno. No planejamento inicial, os alunos poderiam, junto com seus colegas e seu professor, delimitar um problema em sala de aula - aqui caberiam aulas expositivas, por exemplo, dos professores e pesquisadores da Faculdade de Odontologia (FO) -, levantarem hipóteses e ensaiarem desenhos experimentais para testar essas hipóteses. Em seguida, poderiam testá-las nos laboratórios da FO, em visitas específicas para esse fim. De volta à escola, os resultados seriam apresentados e analisados em conjunto, culminando na elaboração de considerações finais do processo. Os resultados do percurso poderiam ser comunicados em local a ser definido.

\section{Implementação}

O grupo de gestores e professores vinculados à DRE Butantã da Secretaria Municipal de Educação de São Paulo recebeu a formação no percurso completo, conduzida pelos docentes responsáveis pelos quatro laboratórios temáticos envolvidos no projeto. A seleção dos temas e laboratórios teve como critérios que o coordenador de cada laboratório fosse docente do Programa de Pós-Graduação em Ciências Odontológicas e que estivesse motivado a participar do projeto

Foram realizados cinco encontros presenciais na FOUSP, com 40 alunos de cada escola. A primeira atividade envolvia a identificação dos alunos e uma conferência introdutória no auditório da faculdade, onde a história do Brasil, da USP e da FO se entrelaçaram numa narrativa que trouxe para os estudantes, professores do ensino fundamental e equipe gestora, a contextualização evolutiva e temporal, desde o surgimento da USP até a atualidade.

A seguir, os estudantes foram distribuídos em quatro grupos, cada um incumbido de desenvolver as atividades planejadas para cada um dos seguintes laboratórios.

\section{Laboratório de Antropologia e} Odontologia Forense, Departamento de Odontologia Social): neste laboratório, o conceito de identidade foi entendido a partir da moldagem de um segmento do arco dentário superior de cada aluno, observando-se e apontando-se caracteristicas da sua individualidade. $\mathrm{O}$ processo de identificação foi desenvolvido com a mordida do aluno em maçãs e, posteriormente, a comparação do seu registro 
com todas as demais marcas, evoluindo-se para a individualização das suas próprias caracteristicas.

\section{Laboratório de Imagem 3D (Labi-3D):}

neste espaço utilizou-se a tomografia computadorizada, exame de extrema importância para o auxílio do diagnóstico e planejamento de tratamento na Odontologia, pois permite visualizar as estruturas dentomaxilofaciais em terceira dimensão. A interpretação destas imagens é realizada por meio de programas específicos, e permite ao cirurgião-dentista avaliar imagens de diversas afeçõoes maxilofaciais. Os principais conceitos foram transmitidos, usando-se as imagens de exames catalogados no laboratório.

Laboratório de Patologia Molecular: por meio da experimentação de técnica de extração de DNA (ADN - ácido desoxirribonucleico) de uma fruta, a banana, o objetivo desta atividade foi o de aproximar os alunos à ciência e ao ambiente laboratorial.

Laboratório de Microscopia: neste laboratório realiza-se a citologia esfoliativa, uma técnica diagnóstica simples que permite a visualização de células epiteliais em microscopia de luz. Os alunos tiveram a oportunidade de realizar o esfregaço celular de sua própria bochecha e acompanhar todo o processo de confecção das lâminas (esfregaço, fixação, coloração e montagem). No momento de análise das lâminas, em que os próprios alunos manuseraram os microscópios, foram abordados os conceitos básicos de citologia e também do uso de técnicas diagnósticas. Os alunos realizaram fotografias das imagens microscópicas utilizando seus próprios aparelhos celulares.

Em cada um dos grupos de estudantes, foram designados dois deles como relatores, incumbidos de fazer os registros de fotos e vídeos das atividades. Todos os alunos receberam um roteiro para que pudessem, de volta à escola, elaborar seus próprios relatos do experimento vivenciado.

Os relatores de cada grupo constituíram o quinto grupo do Núcleo de Telessaúde, Teleodontologia e Centro de Produção Digital Edmir Matson. Foi criada uma página na rede social FaceBook, na qual os registros em fotos e vídeos feitos pelos estudantes e professores durante as atividades foram inseridos, juntamente com legendas explicativas e comentários sobre as experiências (www.face book.com/experimentando.ciencia?ref=ts\&fref=).

Ao final das atividades de cada laboratório todos se reuniam novamente para que cada grupo relatasse a sua experiência e compartilhasse com os demais o que foi aprendido.

No caso da Escola Municipal de Ensino Fundamental (EMEF) Desembargador Theodomiro Dias, após a realização da visita dos alunos à FO, ocorreram alguns desdobramentos pedagógicos. Os alunos, na sala da informática educacional, pesquisaram sobre os conteúdos que tinham aprendido, ampliando assim os saberes, e prepararam apresentações, que foram utilizadas para a multiplicação do conhecimento vivenciado, construído e compartilhado ao longo das atividades do projeto. Os alunos multiplicadores apresentaram para os outros alunos que não participaram do projeto. Assistiram à apresentação as quatro salas dos $9^{\circ}$ anos, com aproximadamente 120 alunos, e duas salas dos $8^{\circ}$ anos, com 45 alunos; um $5^{\circ}$ ano com 36 alunos; alguns professores da unidade escolar e uma supervisora de ensino. Os alunos multiplicadores também realizaram algumas apresentações durante a mostra cultural realizada no dia 19/11/2016, atividade voltada para toda a comunidade escolar - pais, alunos e convidados. As apresentações foram projetadas em tendas escuras expostas na praça que fica em frente à 
escola.

Como tarefa de casa, o educando realizou a escrita do relato pós-visitação, produção textual na qual pôde registrar suas impressões pessoais sobre as vivências científicas nos laboratórios e sistematizar o que havia aprendido. Também, com base em um modelo de relatório científico oferecido, os alunos produziram seus próprios relatórios, o que possibilitou o exercício da escrita científica e o contato com esse gênero textual importante, que permite aos alunos descreverem, narrarem, refletirem e discutirem sobre os conhecimentos adquiridos com as experiências realizadas nos laboratórios.

A mesma EMEF aplicou aos alunos participantes do projeto a atividade de preparar um relatório pré-visitação e outro após a visita, e pôde-se constatar que o relatório pós-visitação foi bem mais longo e detalhado para todos os estudantes.

Uma página sobre o projeto pode ser consultada no website da FOUSP (http://www. fo.usp.br/pos/?p=4845).

\section{Repercussão}

Reportagem recente do Jornal Folha de São Paulo mostra que estudantes oriundos de famílias de baixa renda expressam a diferença entre o que viviam na escola pública de ensino médio e o que encontraram na universidade. Universitários dizem que falta informação e incentivo para que os alunos da rede pública tentem o vestibular de uma universidade como a USP9 .

"Eu nem sabia o que era ENEM, Fuvest. Quando a gente é pobre, não tem referência. As minhas eram o Neymar, o Ganso. Queria jogar futebol." (Abidan da Silva, 19, aluno da Escola Politécnica) ${ }^{9}$.

Um dos principais objetivos do projeto Experimentando Ciência foi o de aproximar a educação básica da educação superior, promovendo oportunidades de que o conhecimento produzido por meio da ciência e tecnologia no nível da pós graduação possa ser minimamente "traduzido" e apropriado por estudantes da educação básica, como mais uma forma de vivência da iniciação científica.

Os docentes que participaram do projeto, ainda que tenham tomado a iniciativa entendendo que ele seria bem sucedido, relataram posteriormente durante a etapa de avaliação do projeto, que foram surpreendidos pelo aproveitamento e compreensão demonstrados pelos estudantes do ensino fundamental, em relação às experiências dos laboratórios e conceitos aprrendidos. Outro aspecto interessante demonstrado foi o de que alguns estudantes manifestaram que antes da visita à FOUSP e da experiência, nunca tinham estado numa universidade, tido acesso a esse tipo de experimentação, ou imaginado que futuramente poderiam ser eles mesmos, universitários. Relataram ainda que passaram a considerar esta possibilidade.

Conforme relatório da EMEF Desembargador Theodomiro Dias, a comparação entre os relatórios pré e pós-visitação elaborados pelos estudantes permitiu identificar que a aprendizagem aconteceu de modo prático e dinâmico. Os alunos vivenciaram e se apropriaram das metodologias das experiências científicas e se envolveram em uma atmosfera favorável de ensino-aprendizagem. Foi observado que muitos conceitos que são complexos para o entendimento quando trabalhados apenas em aulas teóricas, se tornam de fácil entendimento e são fixados de modo lúdico e prático.

A elaboração dos relatórios e da apresentação proporcionou a sistematização e a consolidação das aprendizagens, o que nos mostra a necessidade de práticas de experimentação científica estarem aliadas às práticas de escrita para que haja a potencialização 
da aquisição de conhecimentos científicos no ambiente escolar. Durante as aulas de ciências foram utilizados vários conceitos aprendidos nas oficinas realizadas na Universidade. Muitas vezes, os alunos participantes, ajudaram a explicar ou exemplificar aos outros colegas de classe os conceitos trabalhados e destacados em aula.

\section{CONSIDERAÇÕES FINAIS}

A formulação e implementação compartilhada entre os docentes do Programa de PósGraduação em Ciências Odontológicas da FOUSP e gestores, coordenadores pedagógicos e professores do ensino fundamental vinculados à DRE Butantã, Secretaria Municipal de Educação de São Paulo foram bem sucedidas nos objetivos propostos de promover a articulação entre a pósgraduação e a educação básica e a popularização da ciência e tecnologia, tendo favorecido e ampliado a perspectiva do processo de ensinoaprendizagem dos estudantes. A experiência foi também capaz de despertar nos estudantes a percepção de que a educação superior é uma etapa mais avançada no ciclo educacional, e que poderá ser alcançada por eles, desde que persistam no esforço e desempenho. A implementação do projeto também demonstrou a viabilidade e importância do conhecimento interdisciplinar, e da articulação entre os diferentes níveis educacionais.

\footnotetext{
ABSTRACT

The Guideline of the National Postgraduate Plan for articulation with Basic Education: reporting the project Experimenting Science

The Brazillian National Postgraduate Plan recommends that the National Graduate System develop studies in view of the needs and interests of students in basic education. Seeking to follow this guideline, the Graduate Program in Dental Sciences, School of Dentistry, University of São Paulo established a partnership with management
}

bodies of the public education network in the city of São Paulo, formulating and implementing the Experimenting Science project. The objective was to bring the students of basic education closer to scientific knowledge, produced in the university, promoting the popularization of science and technology. From the delimitation of a problem in the classroom, four groups of ten students, ran five college labs, with the purpose of hypothesizing and testing experimental designs. Throughout the year 2016, five schools participated, making a total of 200 students. The results were presented in the form of reports, reports of experience, and disseminated to the school community, in order to share and multiply knowledge. According to the reports, students had the opportunity to broaden the understanding of science in a practical way, instigating curiosity for research and awakening the perception that higher education is a possible stage of achievement in the educational cycle. For the university, the project demonstrated the feasibility and importance of the interdisciplinary articulation and between the different educational levels.

Descriptors: Education, Primary and Secondary. Science. Health Sciences. Education, Higher. Health Human Resource Training.

\section{REFERÊNCIAS}

1. Brasil. Ministério da Educação. Diretrizes Curriculares Nacionais para o Ensino Fundamental de 9 (nove) anos. Diário Of da União. 2010;1-44. [Acesso em 19 fev. 2017]. Disponível em: http://portal.mec. gov.br/index.php?option=com_docman\&v iew $=$ download\&alias $=6324$-pceb011-10\& category_slug=agosto-2010-pdf\&Itemid= $\underline{30192}$

2. Martins CB. Balanço: o papel da CAPES na formação do Sistema Nacional de PósGraduação. In: Ferreira MM, Moreira RL. CAPES 50 anos: depoimentos ao CPDOC/FGV. Rio de Janeiro: Fundação Getúlio Vargas, 2003. p. 294-309. [Acesso 
em 19 fev. 2017]. Disponível em: http:// cpdoc.fgv.br/producao_intelectual/arq/131 9_Capes11.pdf

3. Scimago Lab. Country Rankings. SCImago Journal \& Country Rank. 2017. [Acesso em 19 fev. 2017]. Disponível em: http://www.scimagojr.com/countryrank.php

4. UNESCO. Educação para todos. 2015. [Acesso em 21 fev. 2017]. Disponível em: http://www.unesco.org/new/pt/brasilia/edu cation/education-2030/education-for-all/

5. Brasil. Emenda Constitucional $\mathrm{n}^{0} 59$. Diário Oficial da União. Brasília, DF; 2009 Nov 12. [Acesso em 21 fev. 2017]. Disponível em: http://portal.mec.gov. br/index.php?option=com_docman\&view =download\&alias=1839-pec-dru-121109pdf\&category_slug=novembro-2009-pdf\& $\underline{\text { Itemid }=30192}$

6. Instituto Brasileiro de Geografia e Estatística - IBGE. Pesquisa Nacional por Amostra de Domicílios. 2012. [Acesso em 21 fev. 2017]. Disponível em: https:// www.ibge.gov.br/home/estatistica/popula cao/trabalhoerendimento/pnad2012/defaul t_sintese.shtm
7. Fernandes R. Índice de Desenvolvimento da Educação Básica (IDEB): metas intermediárias para a sua trajetória no Brasil, Estados, Municípios e escolas. Instituto Nacional de Estudos e Pesquisas Educacionais Anísio Teixeira - INEP. 2005;1-23. [Acesso em 19 fev. 2017]. Disponível em: http://download.inep. gov.br/educacao_basica/portal_ideb/o_qu e_sao_as_metas/Artigo_projecoes.pdf

8. Brasil. Ministério da Educação. Coordenação de Aperfeiçoamento de Pessoal de Nível Superior. Plano Nacional de Pós-Graduação - PNPG 2011-2020. Coordenação de Aperfeiçoamento de Pessoal de Nível Superior. 2010 [Acesso em 19 fev. 2017]. Disponível em: http:// www.capes.gov.br/images/stories/downlo ad/Livros-PNPG-Volume-I-Mont.pdf

9. Leite L, Ferrasoli D. Na USP, calouro da periferia é de "outro mundo". Folha de São Paulo. 2016. [Acesso em 19 fev. 2017]. Disponível em: http://www1.folha.uol. com.br/educacao/2016/11/1835997-nausp-calouro-da-periferia-e-de-outromundo.shtml

Correspondência para:

Ana Estela Haddad e-mail: aehaddad@usp.br

Av Prof Lineu Prestes, 2227 Cidade Universitária 05508-000 São Paulo/SP 